\title{
PAIN AND PLEASURE IN PARTNERSHIP BETWEen NORMAL SCHOOL TEACHERS, STUDENT TEACHERS AND UNIVERSITY TEACHERS
}

\author{
DEBORAH FRASER \\ Department of Professional Studies \\ University of Waikato
}

\begin{abstract}
The triad of teacher, student teacher and lecturer has not always been a mutually beneficial liaison. Lecturers have expressed frustration with the constraints of schools and classroom programmes to incorporate approaches they wish to develop with students; teachers have expressed annoyance at the "child banking" nature of some interactions with lecturers and students. Some teachers have felt that their own valuable craft knowledge and skilful teaching practice has been ignored or is seldom acknowledged; students have often been left in the awkward position of having to learn from, and collaborate with, two powerful but sometimes opposing mentors.

This report focuses specifically on teachers' perceptions of the state of their partnership with lecturers and students at the School of Education, University of Waikato. The research questions also illuminate the teachers' concepts of "genuine partnership". and how such partnership can be fostered. Some significant mismatches are revealed between teachers' concepts and lecturers' concepts of what it means to be professional. This report argues that an open dialogue (in various contexts) on what it means to be professional and the fostering of collaborative research may go some way towards achieving a collaborative triad which is mutually beneficial.
\end{abstract}

\section{INTRODUCTION}

In 1985, Keri Hulme won the Booker prize for her novel The Bone People which encompasses a philosophy of partnership which has relevance for education. It is this perception of partnership which forms the basis of this report:

They were nothing more than people, by themselves. Even paired, any pairing, they would have been nothing more than people by themselves. But all together, they have become the heart and muscles and mind of something perilous and new, something strange and growing and great. Together, all together, they are the instrument of change (Hulme, 1983, p.4).

In 1979 the New Zealand Department of Education published a report, Review of Teacher Training which highlighted a number of concerns regarding the quality of teaching practice in schools. Amongst other concerns they specifically drew attention to the issue of partnership:

There is a lack of close coordination between the colleges and schools, a lack of appreciation by many associate teachers of the aims of in-school 
training and a lack of coordination between the stage of college courses and what the student does in school (Department of Education, 1979, pp.32-33).

In response to the concerns outlined in the report, Battersby and Ramsay (1988, 1990) were commissioned to undertake a comprehensive survey of "policies, practices and problems of in-school training for Division A [primary] student teachers at each of the six New Zealand teachers' colleges". (Ramsay and Battersby, 1988, p.7). The major conclusions from their research were that the partnership between colleges of education and primary schools was perpetuating and exacerbating the theory-practice gap and that schools were being used primarily as "child banks", that is, as providers of children for practice rather than being regarded as professional partners in the education of student teachers.

In terms of partnership they found that the triad of teacher, student teacher and university teacher (lecturer) was marked by criticism:

College lecturers were critical of trainees and of Associate and Normal School teachers. Teachers were critical of trainees and teachers' college staff. Trainees were critical of teachers' college staff and associate teachers (Battersby and Ramsay, 1990, p.24).

While criticism can be constructive and enhance professional growth, the criticism they were alluding to was mainly pejorative, in that lecturers were criticised for being out of touch with classroom realities and teachers were criticised for not being up-to-date with contemporary teaching techniques and/or using outdated curriculum materials. Student teachers were criticised in the main for lack of commitment and application. With this plethora of reproach, the future for positive, professionally enhancing partnership appeared to be bleak. Renwick and Vize (1993) also comment on the divisive nature of criticism within the triad. Much of this criticism centred around the perennial theory-practice debate. Student teachers often perceived the teaching practice component and their associate teacher's guidance as the most important and valuable aspect of their preparation to be teachers and "some associates told students that what they were learning in college was a waste of time and would not fit them for the real world of the classroom" (p.92). This perceived dichotomy between the reality of the classroom and the academic courses of teacher education is characterised by the erroneous belief that one is preferable, more relevant and more essential, than the other. Snook (1992) showed frustration with this false dichotomy which threatens to strengthen the polarisation of theory and practice in a profession which can ill afford it. He states:

The continuing controversies about theory and practice in teacher education are among the most obdurate and absurd. In principle, at least, it is quite straightforward. Teachers have a complex task to perform and their preparation needs to be correspondingly complex; their work requires depth of understanding and their education must be correspondingly abstract. But this does not mean, and indeed cannot mean, a reliance on theory and abstractions alone (1992, p.15). 
Coxon, Massey and Marshall (1994) add:

Critical theory recognises no division between theory and practice. It maintains that all theorising is embedded within practice, and that any practice is underlain with theory (p.14).

Theory and practice are complementary; each can serve to strengthen and enhance the other. Instead of being a vehicle for criticism the triad of school teacher, student teacher and university teacher can be a vehicle for enhancing the theory-practice link. Snook (1992) argues that the future should be built upon a supportive, mutually reinforcing, triadic relationship. Snook's intention is not to subscribe to imitation of teaching technique or an apprenticeship model of teacher education. He is not a firm advocate of school-based training for teachers as proposed by Clarke (1992) in the United Kingdom, and Haberman (1991) in the United States. Instead he proposes that teacher education should be at the forefront of transformation of its own practices, and in doing so, at the forefront of transformation of schools. This transformation requires students to acquire both interpretive and applicative knowledge. The school may be the appropriate setting for the latter, but it is not necessarily the ideal setting for the former.

What then are the characteristics of this "positive triadic relationship"? How can the triad strengthen and enhance the theory-practice link? What suggestions do teachers have to improve the state of the partnership? What are their suggestions for change and what are the implications of these?

\section{METHOD}

Data were gathered from all six normal schools in the Hamilton region in November, 1994. Normal schools have a close association with the School of Education and are "specifically designated and staffed for practice teaching" (Battersby and Ramsay, 1990, p.20). The survey pertained to the regular contacts and in-school practice through various courses of the School of Education (SOE), University of Waikato. Student teachers visit normal schools regularly. It is not unusual to spend several hours each week in schools, this work being an integral part of their SOE course work. These contacts are chiefly curriculum-oriented but also include study in the areas of human development and professional practice. (This research did not focus on sustained periods of practicum, variously termed teaching practice, section practicum or teaching related experience).

Seventy-six questionnaires were distributed to the six schools which was one per teacher, and one each for the liaison teacher and principal of each school. A high rate of $82 \%$ of questionnaires were completed and returned. Half of the schools had a $100 \%$ return rate.

The schools had different approaches to filling out the surveys. Most tabled the questionnaire as an agenda item at a staff meeting and discussed it as a staff prior to making their individual responses. One school had the questionnaire as a "news" item during a morning tea break with no whole staff discussion and an expectation on individuals to fill it out in their own time. 
In all but two schools each question was clarified (if necessary) by the researcher in a face-to-face situation. In the other cases, the questionnaire was discussed with the liaison staff members who then presented it to the rest of their staff. The questions included both closed and open types. In accordance with Cohen and Manion (1994), attention was given to avoiding leading questions, high-brow questions and unnecessarily complex questions.

The questions asked teachers to:

- list the SOE courses they had been involved with over the year;

- any other contacts they had;

- explain if they had been adequately briefed by SOE staff;

- describe their preferred lecturer and student teacher behaviours and characteristics;

- describe what they found frustrating when working with lecturers and student teachers;

- explain their greatest challenge in working with lecturers and student teachers;

- recall their most positive partnership experience over the year;

- $\quad$ suggest how partnership with the SOE could be improved; and

- describe how the SOE acknowledges their strengths and add any other significant points.

\section{FINDINGS}

The most frequent contact with the SOE appeared to be with the professional practice, reading/language and physical education courses. The least contact was with human development, health and Māori courses. However, the figures were somewhat misleading in places e.g. science curriculum groups were known to frequently work in schools and yet occupied fifth place, equal with social studies. The contact totals revealed how many classes were involved so a course which uses large groups of children (such as professional practice, physical education and social studies which use half or full classrooms) appears to involve more contact than a course which uses small groups of two or three children. Teachers cited "planning with students" and as a "guest speaker" as their most common other source of contact with the SOE.

The majority of teachers $(90 \%)$ responded that they felt adequately briefed by lecturers for student teachers in-school practice. The main reasons for adequate briefing included having a thorough initial briefing before the students arrived in the school and having a clear written and verbal outline of what was intended. Conversely, when briefing was cited as not adequate (29\%), the reasons given were that there was lack of sufficient detail provided and the role of the teacher herself was not made explicit. Some teachers stated that they were well briefed for some courses but not for others, hence the figures $90 \%$ and $29 \%$.

The teachers $(43 \%)$ preferred to work with lecturers who were well organised both in terms of their preparation of student teachers and their resources. The other notable category of response $(37 \%)$ was for those lecturers who supported both the teachers and their student teachers. Various comments 
made in support of these preferences included: "I prefer to work with lecturers who..."

- $\quad$ are friendly, relaxed and work together with me for the benefit of the student

- make damn sure the students are present and prepared

- brief the staff and present notes

- $\quad$ appreciate our input

- do not suddenly decide they want written evaluations

- $\quad$ have realistic expectations of which both parties are aware.

Some of the teachers also noted that they appreciated it when the lecturer acknowledged and valued them, communicated clearly and effectively and was informative about what was expected.

The value the teachers placed upon planning and organisation was also highlighted in their responses about what they thought of student teachers. All respondents said that they preferred student teachers who were well planned and prepared for activities with children. This included both lesson planning and the preparation of equipment and resources. The majority $(58 \%)$ also preferred student teachers who, in their terms, behaved professionally, which included being punctual, dressing tidily, using correct grammar and leaving the classroom as they found it. The third largest category of response was for student teachers who were enthusiastic and positive (34\%) expressed in comments such as, "I prefer students who..."

- $\quad$ are positive towards pupils

- $\quad$ are enthusiastic and well presented

- $\quad$ are committed, keen to learn and have a love of children.

Frustration with lecturers fell into two main categories, first, frustration when the teacher was not briefed or involved in cooperative planning (16\%) and second, frustration when lecturers did not support their student teachers (16\%). The support alluded to was helping with planning and having the lecturer present during the student teacher's time in the classroom. Other frustrations included when lecturers expected teachers to write evaluations on groups of student teachers when the students were teaching concurrently $(14 \%)$. Some $(13 \%)$ were frustrated when lecturers were not organised, and $11 \%$ cited frustration when lecturers did not check students' preparedness to teach. Protocols such as introducing themselves (6\%) and acknowledging the teacher $(10 \%)$ were noted as absent in a few cases.

In keeping with their preference for well planned student teachers, the majority of teachers acknowledged that their main frustration was with student teachers who were inadequately prepared in terms of their written planning and any equipment required. Fifty-two percent of the teachers surveyed also noted that student teachers' lack of professionalism was a major source of annoyance. This "lack of professionalism" referred to occasions when student teachers:

- chewed gum

- did not turn up 
- used colloquial language

- did not hand in lesson plans or evaluation sheets before they began.

The theory-practice gap, which was highlighted by Ramsay and Battersby (1988) and Renwick and Vize (1993), featured as a reaction to the question about the greatest challenge perceived by the teachers when working with lecturers from the SOE. Although the words "theory-practice gap" were not used by the respondents, $32 \%$ mentioned that the interweaving of teachers' and lecturers' needs, expectations and philosophies provided the greatest source of challenge. Verbatim comments of perceived areas of concern category included:

- knowing what some [lecturers] really expect

- lining up our priorities regarding curriculum objectives and teaching/learning theory with lecturers' priorities and expectations of the students

- $\quad$ trying to interpret their [the lecturers'] jargon

- reinforcing the reality of the classroom

- being able to meet the needs of the [lecturers'] course and being the practical support for the students

- 'being on the same wavelength

- when philosophy or methods of teaching are different

- finding common ground as professionals.

Question nine asked teachers to recall their greatest challenges when working with student teachers. In keeping with their earlier responses, the most commonly cited challenge (22\%) was establishing professionalism with student teachers. This included discouraging absenteeism, and improving such traits as punctuality, appropriate grammar and general professional demeanour. Giving honest yet worthwhile and constructive feedback to student teachers was also listed $(19 \%)$ as an area to be improved. Sixteen percent of respondents also mentioned the need to deal more effectively with student teachers who are inadequately planned.

The teachers were asked to suggest improvements which they would like to see in their partnership with the SOE. Their suggestions focussed on three main areas:

1. More preliminary discussions and planning with lecturers regarding inschool work with student teachers.

2. More social interaction with lecturers to become better acquainted.

3. More contact with lecturers generally, including follow-up and feedback.

A few respondents $(8 \%)$ specifically signalled a need for more professional interaction to discuss new theories.

Their most positive experiences with the SOE were their interactions with particular lecturers and their courses (58\%), and witnessing student teachers' growth $(21 \%)$. Six percent also mentioned their appreciation of lecturers who supported students who needed help. The teachers valued lecturers who were friendly and approachable, who were organised and provided detailed planning (i.e. regarding space considerations required, equipment, group times) and who 
adhered to their planned schedule. They valued lecturers who provided feedback and ensured that their student teachers were well prepared and well organised. Appreciation was also forthcoming of those who were deemed to be "realistic" in the classroom situation and who planned cooperatively with the teacher.

The last question asked the teachers to reflect upon how the SOE acknowledged teachers' strengths. The largest category of response was from $24 \%$ of teachers who felt that the SOE did not acknowledge their abilities. Eleven percent responded that their strengths had been acknowledged through being invited to be a guest speaker. Six percent of respondents felt positive about having their professional judgment relied upon.

The final section of the survey invited teachers make any other comments they felt were significant. The following comments were typical:

- It's difficult to accommodate large numbers of students in small groups at any one time.

- Please use us.

- Attach students to the same class for the whole year so that they get to know the children.

- I am concerned about the overlap between students doing curriculum work and those on section in the same school concurrently.

- It's awkward having only half the class used - hard to plan meaningful activities for the rest of the class.

- It's useful to get feedback as we don't know if we've been useful or not.

- I enjoy working with SOE lecturers and students...children benefit too.

\section{DISCUSSION}

\section{Teachers' views on student teachers}

Returning to the original research questions, it appears that teachers in this survey have clear views on what they perceive a positive triadic relationship to be. They prefer student teachers to be professional which was interpreted as meaning accommodating, neat, tidy, polite, punctual, well-spoken and organised. "Professionalism" was not used to denote critical thinking, informed decision making, confidentiality, healthy scepticism or debate of contemporary educational issues which may be the sort of answers lecturers would give. Some mention of interpersonal skills was made, for example, teachers valued students who acknowledged them and returned children to the classroom after a lesson and communicated afterwards with the teacher. Generally though, as Cameron and Grudnoff (1993) found in their study of principals and beginning teachers, they preferred student teachers who "accommodate easily to the particular culture of their school" (p.3). It could be construed that teachers prefer students who "fit" into the system, who are amenable and compliant and who conform to the status quo. However, $19 \%$ did state that they preferred student teachers who asked questions and shared concerns. This is some indication that teachers value a more critical, reflective, interpretive approach, although it is not clear as to whether the types of questions preferred were those of a pedagogical nature or merely of a functional type. The sharing of concerns indicates that teachers prefer student 
teachers to be courageous about admitting their anxiety or doubt, which serves to strengthen trust and support in the mentoring of students.

The mentoring that occurs between students and teachers can be paternalistic if the teacher holds the expectation that the student requires mastery of certain skills which will enable them to become a proficient teacher over time. In this regard Vygotsky's (1978) notion of the zone of proximal development is relevant wherein the learner is assisted towards performance that they could not achieve alone. While such incremental learning has its place in learning to teach, a more emancipatory and democratic mentoring relationship is one in which each partner views themselves as a learner constructing together a dialogue which is reciprocal and encouraging. This does not imply that teachers do not have a wealth of experience and knowledge to share with students, but rather to imply that in addition to that role, they can engage in exploratory discourse focused on the process of learning and teaching.

Eight percent of respondents stated that they preferred student teachers who were innovative. Considering that the years of teacher preparation are a time when students are not responsible full time for a class of children, and can spend time developing creative approaches based on theories they have explored at the SOE (which are supposed to be in the vanguard of pedagogical knowledge), there seems to be a paucity of regard for innovation. This may be partially explained however, by the absence of any rating scale within the survey, which included creativity and innovation.

Teachers may have more regard for innovation than this research suggests as they may have rated it highly had they had it on a rating scale of options to choose from. It cannot be claimed that they devalue innovation and/or creativity in student teachers. What is interesting, though, is how rarely such characteristics came to mind. Nor did risk-taking. It could be argued that unless a teacher personally valued innovation, the preference for other traits in students would ensure that this particular faculty would not have achieved a high degree of consideration. Perhaps teachers value innovative lessons when they see them and perhaps they admire the creativity of some student teachers, but most did not cite such traits as a preference in student teachers. However, the most creative accomplishments are built upon a well-grounded knowledge base and student teachers are more likely to be effectively creative in an area that they are already conversant with. Lecturers and teachers should provide opportunities for student teachers to develop creative, innovative lessons in their areas of strength, and provide opportunities for student teachers to encourage children's creativity.

Induction to teaching requires tolerance of ambiguity as student teachers learn to be both firm and caring with children, structured and flexible with their planning, compliant and creative in the school environment. Lecturers and teachers have a key role in exploring the dimensions of these paradoxes and assisting student teachers to live with and develop these. Furthermore, Gallimore, Tharp and John-Steiner claim that:

Creative work requires a sense of trust in oneself that is virtually impossible to sustain alone. (in press) 
From their examination of effective mentoring relationships (including the mentoring of creative individuals) Gallimore, Tharp and John-Steiner found that the engagement of students with an effective mentor enabled the student to build a sense of self-knowledge concomitant with their technical knowledge. Ongoing communication with a more experienced "other" assisted their persistence and enabled them to focus on processes, not just products of learning and teaching. A relationship such as this requires considerable trust between members of the triad in addition to some preservation of autonomy and identity. Collaboration of students with teachers and lecturers may become imitative if the novice is always cast as the recipient of advice and guidance.

\section{Being professional}

Being creative and innovative need not detract in any way from being professional. Student teachers need to be responsible, honest and show integrity; after all, they will be entering a profession which requires them to care for and teach present and future generations of children. As such they should be punctual, well planned and proficient in their organisation to make the most of the precious time they have with the minds and lives of children. This professionalism need not be a synonym for mindless conformity and uncritical acceptance of everything they encounter. Indeed, the very nature of teacher education includes the development of critical thinking and analysis to enable student teachers to do more than passively participate and reproduce current, and sometimes dated, practice. This places the student teacher in an unenviable, invidious position at times, "sandwiched" as they are between their associate teacher who may have one set of expectations, and their lecturer who may have another (see also Calder, Faire and Schon, 1993; McGee, Oliver and Carstensen, 1994).

The teacher education triad should be a supportive arrangement where issues such as expectations are clarified with some reaching of consensus to enable the student teacher to grow from an informed and courageous base. They should be informed in that their teaching is well grounded in an understanding of curriculum, learning theory and pedagogy; and courageous in that the triad can mentor and foster the student teacher's constructive attempts at growth.

In working with student teachers, normal school teachers cited establishing professionalism as their biggest challenge. This was also a major source of frustration for them. What it means to be professional then, should be clearly articulated, explored and critiqued with student teachers so that their induction to teaching incorporates their induction to a profession, as significant and important as a profession in law, medicine, or business. This professionalism forms the foundation of their teacher education, underpinning their construction of applicative and interpretive knowledge and their practical experiences and critical theory building.

Carpenter and Byde explored the development of student teachers' professional self-concepts which they suggest are "associated with high levels of occupational commitment" (1994, p.174). However, they found a marked difference between primary and secondary student teachers. Secondary student teachers regarded their course work and in-school work as complementary to 
developing their role as professionals. In contrast, primary student teachers placed much greater emphasis on their in-school practice which "became the dominant influence in their professional socialisation" (p.175). They tended to view their course work unfavourably, as conflicting or competing, with their practicum experiences. Such findings underline how important it is to articulate what it means to be "professional" and to develop professional self-concepts both in the school and the SOE, rather than in one site at the expense of the other.

\section{The theory-practice gap}

The "gap" is not the simple distinction that it has been portrayed as being, where the SOE is the site of theoretical learning and the school is the site of practice. Instead, the more prominent gap is that which frequently exists between teachers' theories and practices and lecturers' theories and practices. The polarisation is not an either/or option between practicum and principles. There appear to be some contradictory, rather than complementary theories and practices at both university and school sites creating some problems with communication.

Generally, this research suggests that teachers are eager to improve communication with the SOE especially with preliminary discussions which "set the scene" for expectations and requirements of each party in the triad. They were also eager to receive feedback from lecturers for their information and professional growth. Eight percent of respondents specifically stated that they would welcome professional discussions on theoretical issues relevant to teacher education. Rather than being dismissive of theory, most teachers signalled a desire for more communication, in various forms, to improve the links between university course work and in-school practice. Some also indicated that they had theories and innovative practices which they wished to share. Such a response indicates a request for genuine partnership through joint dialogue.

\section{Child banks}

Battersby and Ramsay's conclusion that the school-based experiences of students are based on "a banking concept" (1990, p.26) is not well supported by this research. However, some teachers $(16 \%)$ felt that they were not briefed enough or involved in cooperative planning. The same percentage felt that lecturers did not support student teachers enough and were not visible in classrooms during the teaching sessions. Such responses indicate that some aspects of child banking are occurring in some situations. As Battersby and Ramsay pointed out, the marked desire for normal school teachers to become more fully involved in the education of students is apparent in their suggestions for increased contacts, and preliminary discussions and interaction with SOE staff. Further research is required to elaborate further on the $58 \%$ who cited very positive partnerships with particular lecturers and courses. These partnerships could be investigated to ascertain how they are organised and fostered so effectively. 


\section{Increased in-school training}

Teachers did not express a desire to have increased in-school training of student teachers as proposed by Clarke (1992), but instead expressed their appreciation of a triadic partnership model. However, teachers in one country school said that they would appreciate being used more, including more contact with second and third year students.

\section{Feedback}

Giving feedback was highlighted as a growth need by teachers (19\%) in terms of assistance with giving feedback to student teachers that is honest and constructive. The giving of high quality feedback is an essential skill for teachers to continue to develop as they work with student teachers, children, colleagues and the community. Feedback was also sought by teachers from lecturers. They clearly appreciated those lecturers who communicated frequently and effectively. Ethically it is becoming increasingly important for lecturers to keep teachers fully informed of their purposes for in-school work and this information should include feedback during and after the process.

\section{Teachers' views on partnership with lecturers}

According to teachers, the state of the partnership appears to be effective and productive when lecturers:

- consult with teachers before in-school practice, clarifying expectations

- involve teachers in cooperative planning

- $\quad$ are organised and provide notes

- $\quad$ appreciate the teachers' input

- $\quad$ are friendly, relaxed and approachable

- work with the teacher to support the student

There was a strong emphasis on communication which is open, clear and consistent. The value of positive and appropriate communication was highlighted by lecturers when interviewed about their views on effective relationships with teachers (Calder, Faire and Schon, 1993). A quote from their reseaich illuminates a key factor in effective communication:

Her [the teacher's] body language was always receptive...she was as keen to hear what I had to say as I was to hear what she had to say. (p.7)

This active listening by both parties is crucial if both are to feel valued as partners and characterises "a collaborative partnership rather than...a paternalistic ideology" (Ramsay and Battersby, 1988). Such a collaborative partnership draws upon the strengths and insights of each party. A quarter of the teachers felt that their strengths had not been acknowledged by the SOE staff and typical comments included: 
- The SOE has no idea what my strengths are.

- Does the SOE really know staff strengths?

Although a booklet is provided to all SOE lecturers outlining what strengths normal school staff have, there is some indication that some teachers feel that this is disregarded. The partnership which Hulme celebrates in the introduction of this paper, refers to a situation where the whole is greater than the sum of each of its parts. Not only can the partnership achieve something more effective and larger than any individual but it can also be the vehicle, the instrument, the catalyst for change. This dynamic evolving growth should be the pivotal focus of the partnership. In this way, the teacher, student teacher and lecturer support each other in a democratic fashion. Each party learns to be critical, to give effective feedback, to elucidate theoretical positions, to link theory to practice and to plan adventures in teaching together which go beyond reproduction and seek emancipatory transformation (Bourdieu, 1977).

\section{Collaborative research and reform}

New Zealand (Aotearoa) is often hailed as innovative and progressive in education with its strong tradition of child-centred, holistic learning in primary schools, and the rapid advent of self-managing schools. Many overseas educators are attracted to Aotearoa as a model of exemplary practice. One example is a visit by some staff from the Education Faculty at Rochester University in the United States. After an examination of teacher education at Waikato and Wellington, they plan to restructure their teacher education programme to improve their partnership with elementary schools and to incorporate educational issues and practices (Hursh, 1994). They aim to create a "community of learners" (Hursh, 1994, p.1) among teachers, principals, parents, students and university faculty. They intend to involve teachers in action research with the support and collaboration of university faculty, and this research is intended to become the focus for staff development in the surrounding schools. This builds upon the Philadelphia Schools Collaborative Project (cited in Hursh, 1994) which emphasises "the necessity for school and university improvement to be based on educators' active research on their own institutions" (ibid., p.1). The triad would then be involved as partners in research and reform in education, situated in the school as a site of innovation.

Collaborative research and reform with teachers in normal schools in Hamilton is occurring, but not at the level or to the extent that Hursh plans. Faculty at Rochester have complimented the University of Waikato on its partnership model, but are already planning to move beyond it. To be "the instrument of change" (Hulme, 1983, p.4) we need to develop more collaborative research projects with colleagues in schools so that professional growth is mutual and beneficial for all (Lather, 1986). 


\section{CONCLUSION}

The in-school practice of students should be more than an uncritical practice ground for trying what appears to "work" without questioning who is benefiting and who may be disadvantaged. This requires a reflection upon social and cultural dimensions in the school environment and the wider community. The partnership between schools and universities or colleges of education, enables student teachers to practice teaching and develop critical interpretive knowledge to inform that practice. In-school practice should also be a site for research, innovation and genuine partnerships for student teachers, school teachers and university teachers.

This research highlights normal school teachers' views on how they perceive the current state of the partnership with the SOE of the University of Waikato. For school-based training to be enhanced and strengthened it seems that communication must continue to be improved. A starting point would be to investigate those courses identified as effective in forming partnerships to ascertain their communication procedures. There also needs to be further opportunities for teachers to participate in SOE planning and decision-making processes.

Recognition and encouragement needs to be given to innovation. The triad can be an ideal supportive environment. for participants to take risks without being at risk, to discover what is possible rather than just what is passable. Notwithstanding the initiatives that are underway, collaborative research and reform could be further developed in normal schools so triads undertake more research on their own practices. It is claimed that New Zealand is the first country in the world to include visual language as a compulsory part of the English curriculum ("World interest", 1995). Considerable interest is being conveyed internationally as to how it will be introduced into schools. This seems to be a key area for school-university partnerships where professional development, action research and children's learning can be documented, evaluated and enhanced.

This research points to a need for more professional discussions which assist in interweaving the needs, philosophies and expectations of teachers and lecturers. These discussions could take the form of regular educational forums situated in schools and at the SOE. Both sites are necessary in order to emphasise the reciprocal nature of the partnership. Some forums of this nature have occurred previously but a more systematic, sustained approach appears to be timely if the goal of partnership is to be achieved.

\section{ACKNOWLEDGEMENTS}

My grateful thanks go to the staff of normal schools who gave of their time to complete the survey which forms the basis of this article, and for their interest and enthusiasm for the topic. I am also appreciative of research assistance from Whakarongo Tauranga who collated the raw data. 


\section{REFERENCES}

Battersby, D., \& Ramsay, P. (1990). Practice teaching in New Zealand: policies, practices and problems. South Pacific Journal of Teacher Education, 18(1), pp.19-26.

Bourdieu, P. (1977). Reproduction in education, society and culture. London: Sage Publications.

Calder, I., Faire, M., \& Schon, P. (1993). The teaching practice experience: The perspectives of the supervising lecturers. Hamilton: Professional Studies Department, University of Waikato.

Cameron, M., \& Grudnoff, L. (1993). What principals think of their beginning teachers. Set 2, item 15.

Carpenter, P., \& Byde, P. (1994). The development of professional self-concept. South Pacific Journal of Teacher Education, 22(2), pp.163-176.

Clarke, K. (1992). Address to the North England Education Conference.

Cohen, L., \& Manion, L. (1994). Research methods in education (4th ed.). London: Croom Helm.

Coxon, E., Massey, L., \& Marshall, J. (1994). Introduction. In E. Coxon, K. Jenkins, J. Marshall \& L. Massey (Eds.), The politics of learning and teaching in Aotearoa New Zealand. Palmerston North: Dunmore Press.

Department of Education (1979). New Zealand review of teacher training. Wellington: Department of Education.

Gallimore, R., Tharp, R. \& John-Steiner, V. (in press). The developmental and sociohistorical foundations of mentoring. The MacArthur Foundation.

Haberman, M. (1991). The dimensions of excellence in programs of teacher education. IFA Education Policy Unit, Study paper 26.

Hulme, K. (1983). The Bone People. Wellington: Spiral.

Hursh, D. (1994). Collaborating for children project: Developing learner-sensitive schools through university-school collaborative research and reform. Unpublished manuscript, Teaching and Curriculum Department, University of Rochester.

Lather, P. (1986). Research as praxis. Harvard Educational Review, 56(3), pp.257-277.

McGee, C., Oliver, D., \& Carstensen, M. (1994). The teaching practice experience: The perspectives of student teachers. Professional Studies Department, University of Waikato.

Ramsay, P., \& Battersby, D. (1988). A study of in-school training for Division A student teachers. Final Report. (Research contract 41/17/158). New Zealand Department of Education.

Renwick, M., \& Vize, J. (1993). Windows on teacher education. Student progress through Colleges of Education and the first year in the classroom. The final report. Wellington: NZCER.

Snook, I. (1992). Teacher education: A sympathetic appraisal. Keynote address to the conference, Teacher education: an investment for New Zealand's future. Auckland: Auckland College of Education.

Vygotsky, L. S. (1978). Mind in society: The development of higher psychological processes. Cambridge, MA: Harvard University Press.

World interest in curriculum, say Britons. (1995, January). Waikato Times, p.8. 